\title{
Oral health and quality of life: an epidemiological survey of adolescents from settlement in Pontal do Paranapanema/SP, Brazil
}

\author{
Saúde bucal e qualidade de vida: um estudo epidemiológico de \\ adolescentes de assentamento no Pontal do Paranapanema/SP, Brasil
}

\begin{abstract}
Milene Moreira Leão ${ }^{1}$
Cléa Adas Saliba Garbin ${ }^{1}$

Suzely Adas Saliba Moimaz ${ }^{1}$

Tânia Adas Saliba Rovida ${ }^{1}$
\end{abstract}

${ }^{1}$ Odontologia Infantil e Social, Faculdade de Odontologia de Araçatuba, Universidade Estadual Paulista. R. José Bonifácio 1193, Vila Mendonça. 16015-050 Araçatuba SP Brasil. mileninhamoreira@ yahoo.com.br

\begin{abstract}
This study aimed to verify oral health, treatment needs, dental service accessibility, and impact of oral health on quality of life (QL) of subjects from settlement in Pontal do Paranapanema/SP, Brazil. In this epidemiological survey, 180 10-to 19-years old adolescents enrolled in the school that attend this population in settlement underwent oral examination, to verify caries index (DMFT- decayed, missing and filled teeth) and periodontal condition (CPI), and were interviewed using the World Health Organization Quality of Life (WHOQOL-Bref) and Oral Impact Daily Performance (OIDP) instruments to evaluate QL, and the Global School-Based Health Survey (GSHS) about dental service accessibility. DMFT average was 5.49 ( \pm 3.33 ). Overall, $37.2 \%$ of participants showed periodontal problems, mainly CPI $=1$ (77.7\%). Treatment needs were mainly restorations. GSHS showed that the last dental consultation occurred $>1$ year previously for $58.3 \%$ of participants at a public health center (78.9\%). The average WHOQOL-Bref was 87.59 $( \pm 15.23)$. Social relationships were related to dental caries and health service type. The average OIDP was 6.49 ( \pm 9.15$)$. The prevalence of caries was high and observed periodontal problems were reversible. The social relationships of adolescents from settlement were influenced by caries and health services type.
\end{abstract}

Key words Oral health, Quality of life, Adolescent
Resumo O objetivo deste trabalho foi verificar a saúde bucal, as necessidades de tratamento, o acesso aos serviços odontológicos e o impacto da saúde bucal na qualidade de vida $(Q V)$ de adolescentes de assentamento no Pontal do Paranapanema/SP, Brasil. Neste estudo epidemiológico, foram examinados 180 jovens entre 10 e 19 anos matriculados na escola que atende a esta comunidade para verificar o indice de cárie (CPOD - cariados, perdidos e obturados) e a condição periodontal (IPC); e entrevistados, utilizando-se os instrumentos World Health Organization Quality of Life (WHOQOL -Bref) e Oral Impact Daily Performance (OIDP) para avaliar qualidade de vida e o Global School-based Health Survey (GSHS-WHO) visando o acesso. O CPOD médio foi 5,49 ( $\pm 3,33)$ e 37,2\% tinham problemas periodontais, predominando $I P C=1(77,7 \%)$. As necessidades de tratamento concentraram-se nas restaurações. O GSHS mostrou que a última consulta odontológica foi realizada nos últimos 12 meses (58,3\%), e 78,9\% no serviço público. A média WHOQOL-Bref foi $87,59$ ( $\pm 15,23)$. O dominio relações sociais teve associação com a cárie e o local do atendimento. A média OIDP foi 6,49 $( \pm 9,15)$. A prevalência de cárie foi alta e os problemas periodontais ainda eram reversíveis. As relações sociais foram influenciadas pela presença de cárie e pelo local do atendimento.

Palavras-chave Saúde bucal, Qualidade de vida, Adolescente 


\section{Introduction}

Recent research has examined adolescents' conceptualizations of and satisfaction with quality of life, as well as their well-being ${ }^{1,2}$. Well-being and health-related quality of life are measured using the physical, social relationships, psychological, and environmental domains ${ }^{2}$.

Oral health is an important indicator of adolescents' quality of life independently of domains, but especially in the social relationships domain due to halitosis and concern with appearance ${ }^{1,3}$. Dental caries and periodontal disease are the oral health factors that cause the most pain and embarrassment among adolescents. Rural populations have shown extremely poor oral health characterized additionally by early tooth loss, despite public health policies and technological advances in dentistry ${ }^{4}$. The psychological and social impacts of oral health problems can compromise adolescents' quality of life ${ }^{5}$.

In Brazil, oral health is worse in rural than in urban populations, posing a major burden on the public health system ${ }^{6}$. In the state of São Paulo, the decayed, missing, and filled teeth (DMFT) index was found to increase three-fold between the ages of 11 and 19 years (2 vs. 6), reflecting the worsening of oral health during adolescence ${ }^{4}$. However, national surveys have documented a decline in the DMFT index from 6.1 in 2003 to 4.2 in 2010 among 15-19-year-olds ${ }^{7,8}$.

The high caries index and prevalence of periodontal disease suggest that inequality of access to dental services affects rural adolescents, who can be considered to be a socially excluded population due to residence in remote areas ${ }^{9}$. Despite the presence of health centers in rural areas, the difficulty of transport to these centers, lack of capable professionals, and suboptimal center infrastructure can pose barriers that negatively impact adolescents' health ${ }^{9}$, similarly in rural settlements because of geographic setting.

Rural settlements in Brazil have been built with land reform, involving national government, the landless and farmers front many violent conflicts. In anticipation of land reform, families invade land considered to be unproductive and live there without sanitary services. In this manner, settlements are created and populations organize to seek the right of access to public health services. However, they are located in remote areas and must overcome obstacles to health care access ${ }^{10}$.

In this context, the aims of this study were to determine the oral health conditions, access to dental services, self-perceived quality of life, and impact of oral health on quality of life among Brazilian adolescents from rural settlement.

\section{Methods}

\section{Study design and participants}

All 349 adolescents aged 10-19 years old who lived in rural settlement in Caiuá, São Paulo State, Brazil, were invited to take part in this cross-sectional epidemiological study. São Paulo Lake Project School is the only educational institution which attends this community that is also located into rural settlement. Considering that all of adolescents were participants in the Family Aid financial national incentive program, which requires regular school attendance, this school was considered the better setting to find all adolescents and to conduct this research.

After approval by the Committee for Ethics in Human Research of Univ. Estadual Paulista - UNESP, School of Dentistry - Araçatuba, the study purpose and procedure were explained to adolescents' parents. Parents provided written informed consent to adolescents' participation and the study was conducted in accordance with all ethical guidelines. Adolescents who agreed to take part in the research, answered all questions, and permitted oral examination were included in the study.

Data collection was performed through oral examination and interviews.

\section{Oral examination}

Oral examinations were conducted to calculate DMFT caries index (decayed, missing and filled teeth) and a community periodontal index (CPI) for each adolescent participant. The CPI was used to classify periodontal conditions in sextants of the maxilla and mandible as healthy (0) or to indicate the presence of gingival bleeding (1), dental calculus (2), periodontal pocket of 4-5-mm depth (3), and periodontal pocket of $\geq$ $6 \mathrm{~mm}$ depth (4).

A pilot study was conducted earlier this research with adolescents who lived in other settlement in Presidente Venceslau-SP, aiming to test questionnaires and to train the researcher who had 0.88 in Kappa test for dental caries.

The oral examinations were conducted by this trained researcher, who was properly attired, using mirror and probe to verify caries index and 
periodontal condition. These examinations were performed under the World Health Organization's (WHO's) recommendations for epidemiological surveys.

\section{Measures}

The same researcher conducted the interviews of students during class periods at the schools, in local reserved to avoid embarrassment and coercion. It was previously scheduled and when some student was not present, three consecutive attempts were executed. The absence of student in all of attempts, result in exclusion of sample.

The validated Portuguese versions of the World Health Organization Quality of Life (Brief) questionnaire (WHOQOL-Bref) ${ }^{11}$, Oral Impacts on Daily Performance (OIDP) index ${ }^{12}$, and the World Health Organization's Global School-Based Student Health Survey (GSHS) ${ }^{13}$ questionnaires were used to guide interviews. Although these instruments can be self-administered, the researchers administered them in an interview setting to ensure participants' comprehension and reduce the possibility of false answers, thereby controlling for common biases.

The WHOQOL-Bref is a 26-item instrument developed by the WHO to evaluate quality of life in the physical, psychological, social relationships, and environmental domains, with two additional questions about self-perceived quality of life and health. Responses to all items are structured by a five-point Likert scale ranging from 1 (never/nothing/very dissatisfied) to 5 (always/ completely/very satisfied). Higher scores indicate better quality of life, except for items related to pain and discomfort, negative feelings, and medication dependence, which have inverted scales. Domain scores are calculated by summing responses to all items in that domain ${ }^{11}$.

The OIDP index measures the impact of oral health on quality of life. It was developed originally for children and was later adapted for use in older populations, including adolescents. The instrument has two components: the first section solicits information about adolescents' self-reported oral problems in the past 3 months using a list of 17 problems and an open "other" item, and the second component is used to evaluate the effects of problems reported in the first section on eight daily activities of adolescents (eating, speaking, cleaning the mouth, sleeping, maintaining an emotional repertoire, smiling, doing homework, and engaging in social socializing).
The impacts of oral problems on quality of life are measured according to severity (none, few, moderate, severe) and frequency (always, sometimes, never) using a Likert scale ranging from 0 (none/never) to 3. Severity scores are multiplied by frequency scores to obtain an index for each daily activity (range, $0-9$ ). The total OIDP score (range, 0-72) is obtained by summing all totals for the eight daily activities; the overall OIDP index is calculated by multiplying by this score by 100 and dividing by 72 to create a scale ranging from 0 to 100 . Higher scores indicate a greater impact of oral health on quality of life $\mathrm{e}^{12}$.

The WHO developed the GSHS in 2003 and improved it in $2009^{13}$ to evaluate health risk behaviors among adolescents according to demographic profile, with the aim of collecting data to support the planning and implementation of new programs and policies focused on adolescent populations, mainly in school environments. In this study, 27 GSHS items on oral hygiene habits and dental service accessibility were used. It has no score, but show behaviors of study population.

\section{Statistical analysis}

Descriptive analysis about DMFT and CPI index, all questions of GSHS, WHOQOL-Bref and OIDP instruments, was first conducted to characterize the study sample. The normality of data distribution related to WHOQOL-Bref and OIDP was examined using the Shapiro-Wilk test. Bivariate analyses were conducted using the chisquared, Fisher's, and Mann-Whitney tests, with calculation of $95 \%$ confidence intervals, which outcomes were variables related to quality of life. The independent variables were all question of dental services accessibility, DMFT and CPI indices. The same testes were applied in other bivariate analysis to test the influence of dental services accessibility on oral health condition (DMFT and CPI). A multivariate logistic regression model was constructed using variables showing statistical significance of $95 \%$ confidence intervals in bivariate analyses. All analyses were performed using BioEstat 5.3 and SPSS 20.0 software.

\section{Results}

Of 349 eligible participants, 32.9\% moved, 7.5\% withdrew from the study, $1.1 \%$ died, $4.0 \%$ refused study participation, and $2.9 \%$ did not answer all interview questions or did not allow oral 
examination. The final study population thus comprised $180(51.6 \%)$ adolescents.

The mean DMFT index was $5.49 \pm 3.33 ; 6.7 \%$ of adolescents had DMFT indices of 0 Dental caries was associated with age $(p<0.001)$ according to the Mann-Whitney test, but the regression model showed no linear progression $(p=0.67)$.

Oral examination findings indicated that the dental treatment needs of the study population were restoration $(86.6 \%)$, extraction $(5.7 \%)$, endodontic treatment $(5.3 \%)$, enamel remineralization $(0.8 \%)$, sealant application $(0.8 \%)$, and fixed prosthesis application $(0.8 \%)$. More than onethird $(37.2 \%)$ of participants showed periodontal tissue alteration; among them, $77.7 \%$ of participants had at least one sextant with gingival bleeding, 20.8\% exhibited dental calculus, and 1.5\% had shallow periodontal pockets ( $\leq 4 \mathrm{~mm}$ depth).

Table 1 shows adolescents' access to dental services according to caries experience and periodontal condition.

The health services type of last consultation with a dentist was related to the need for restoration of one tooth surface $(p=0.03)$. There cause for the last consultation was associated with the same treatment need according to the chi-squared test $(p=0.01)$.

Table 2 shows WHOQOL-Bref domain scores according to quality of life measures.

WHOQOL-Bref variables are distributed symmetrically, but OIDP indices are characterized by an asymmetrical distribution with many outliers. The Shapiro-Wilk test confirmed the asymmetrical distribution of OIDP scores in relation to the presence $(p<0.001)$ and absence ( $p=0.04$ ) of caries. Table 3 shows descriptive statistics for WHOQOL-Bref total and domain scores and the OIDP index; Mann-Whitney tests revealed that dental caries had a major impact on social relationships.

WHOQOL-BREF scores (average $=85.4$ ) were higher among adolescents who sought dental treatment in the past 12 months than among those who consulted a dentist more than 1 year ago $($ average $=80.1)$.

WHOQOL-BREF social domain scores were higher among adolescents who obtained private dental services (average $=61.3$ ) than among whose received public services (average $=54.5$ ), and higher among those who classified the last consultation as "good" (average = 57.0) than among those who classified it as "bad" (average $=53.4$ ). The health service type and quality of the last consultation thus influenced adolescents' social life (Table 4).
WHOQOL-BREF environmental domain scores were higher among adolescents who had received education about oral disease prevention (average $=77.4$ ) than among those who reported receiving no health education (average $=70.16$; Table 4).

\section{Discussion}

This research revealed high caries index and the treatment needs concentrated on restoration and endodontics procedures suggesting the lack of dental care, which problem started in health system or through neglect of oral health by patients.

Preventive and educational measures can avoid the worsening of oral health, but their absence can result in the need for endodontic procedures, provisional restorations, and drug prescription in urgent dental clinics to address severe dental problems and avoid extraction ${ }^{14}$. First molars are most commonly affected because they are the first posterior teeth to erupt, even with deciduous permanence ${ }^{15}$. It is important to highlight that the highest prevalence of decayed component of caries index and gingival bleeding predominance in the present study suggested that there was failed treatment and preventive dental services for that excluded population.

The neglect of oral hygiene, consumption of a cariogenic diet, and non-regularity of consultation with a dentist make the first molars more susceptible to extraction ${ }^{15}$. Considering that the settlement stayed in rural area, it is important to emphasize that rural population which present adolescents with high caries index tend to have a future with tooth loss in adulthood ${ }^{4}$.

In the present research the prevalence of caries was higher among adolescents who sought dental treatment because of pain than among those who presented for routine consultation. Preventive care can avoid dental caries, but it is rarely a part of public health services, which are the main source of dental care for rural and remote populations to maintain oral health ${ }^{15}$, that express the same situation of studied population who live at rural settlement.

Important to observe that the need for restoration of one tooth surface was greater among adolescents who attended public services than among those who consulted dentists in the private sector and adolescents who sought treatment because of pain perceived a greater need for restoration of one tooth surface than did those who made preventive routine dental visits. 
Table 1. Dental service accessibility according to caries experience and periodontal condition among adolescents from settlement.

\begin{tabular}{|c|c|c|c|c|c|c|c|c|c|c|}
\hline \multirow{3}{*}{$\begin{array}{l}\text { Dental services accessibility } \\
\text { (regarding last consultation) }\end{array}$} & \multicolumn{4}{|c|}{ DMFT } & \multirow[b]{3}{*}{ p-value } & \multicolumn{4}{|c|}{ The worst CPI } & \multirow[b]{3}{*}{ p-value } \\
\hline & \multicolumn{2}{|c|}{ DMFT $>0$} & \multicolumn{2}{|c|}{ DMFT $=0$} & & \multicolumn{2}{|c|}{$\mathrm{CPI}>0$} & \multicolumn{2}{|c|}{$\mathrm{CPI}=0$} & \\
\hline & $\mathbf{n}$ & $\%$ & $\mathbf{n}$ & $\%$ & & $\mathbf{n}$ & $\%$ & $\mathbf{n}$ & $\%$ & \\
\hline Timing consultation & & & & & 0.1940 & & & & & 0.2110 \\
\hline < 1year ago & 100 & 60.2 & 5 & 41.7 & & 32 & 58.2 & 73 & 59.3 & \\
\hline $1-2$ years ago & 53 & 31.9 & 4 & 33.3 & & 15 & 27.3 & 42 & 34.1 & \\
\hline 3 or more years ago & 13 & 7.8 & 3 & 25.0 & & 8 & 14.5 & 8 & 6.5 & \\
\hline Local & & & & & 1.000 & & & & & 0.8950 \\
\hline Public service & 132 & 80.0 & 10 & 83.3 & & 43 & 79.6 & 99 & 80.5 & \\
\hline Private service & 33 & 20.0 & 2 & 16.7 & & 11 & 20.4 & 24 & 19.5 & \\
\hline Cause & & & & & $0.0100^{*}$ & & & & & 0.9550 \\
\hline Pain & 40 & 24.1 & 1 & 8.3 & & 12 & 21.8 & 29 & 23.6 & \\
\hline Routine consultation & 89 & 53.6 & 11 & 91.7 & & 31 & 56.4 & 69 & 56.1 & \\
\hline Cavities in teeth & 37 & 22.3 & - & - & & 12 & 21.8 & 25 & 20.3 & \\
\hline Evaluation of received attendance & & & & & 0.8580 & & & & & 0.9330 \\
\hline Terrible/Bad & 5 & 3.0 & - & - & & 2 & 3.6 & 3 & 2.5 & \\
\hline Regular & 44 & 26.5 & 3 & 25.0 & & 16 & 28.6 & 31 & 25.4 & \\
\hline Good & 75 & 45.2 & 6 & 50.0 & & 24 & 42.9 & 57 & 46.7 & \\
\hline Excellent & 42 & 25.3 & 3 & 25.0 & & 14 & 25.0 & 31 & 25.4 & \\
\hline Information concerning preventing & & & & & 0.1120 & & & & & 0.9020 \\
\hline oral problems & 55 & 32.7 & 7 & 58.3 & & 20 & 35.1 & 42 & 34.1 & \\
\hline No & 113 & 67.3 & 5 & 41.7 & & 37 & 64.9 & 81 & 65.9 & \\
\hline Yes & & & & & 1.0000 & & & & & 0.8660 \\
\hline Self-perception of dental treatment & 23 & 13.8 & 1 & 8.3 & & 8 & 14.0 & 16 & 13.1 & \\
\hline needs & 144 & 86.2 & 11 & 91.7 & & 49 & 86.0 & 106 & 86.9 & \\
\hline No & & & & & 0.3130 & & & & & 0.2800 \\
\hline Yes & 124 & 94.7 & 7 & 5.3 & & 93 & 51.7 & 38 & 21.1 & \\
\hline Fear to consult a dentist & 44 & 89.8 & 5 & 10.2 & & 30 & 16.7 & 19 & 10.6 & \\
\hline No & & & & & & & & & & \\
\hline Yes & & & & & & & & & & \\
\hline
\end{tabular}

Table 2. Score according scales of measurements of quality of life.

\begin{tabular}{lccccc}
\hline \multicolumn{1}{c}{ Variables } & Lowest value & Highest value & Median & Average & Standard deviation \\
\hline WHOQOL & & & & & \\
$\quad$ Physical & 50.00 & 100.00 & 85.71 & 85.71 & 10.24 \\
Psychological & 16.67 & 100.00 & 79.17 & 78.17 & 12.83 \\
Socializing & 25.00 & 100.00 & 58.33 & 56.20 & 15.91 \\
Environment & 34.38 & 100.00 & 76.57 & 75.19 & 14.15 \\
WHOQOL score & 25.00 & 100.00 & 87.50 & 83.40 & 15.23 \\
OIDP score & 0 & 44.00 & 0.00 & 6.49 & 9.15 \\
\hline
\end{tabular}

These findings showed that adolescents attend public service used not to do a preventive dental treatment and the pain is the main reason for seeking care. In rural and remote communities, dental caries is a common event in children's life 


\begin{tabular}{|c|c|c|c|c|c|c|}
\hline \multicolumn{7}{|l|}{3370} \\
\hline \multicolumn{7}{|l|}{ 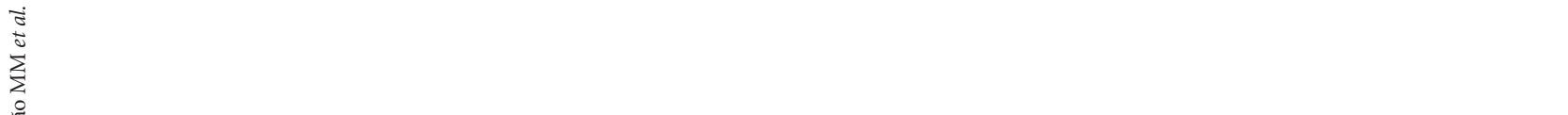 } \\
\hline & \multicolumn{6}{|c|}{ Table 3. WHOQOL-BREF domain scores and OIDP index according to DMFT index. } \\
\hline & Variables & DMFT & Median & Average & Standard deviation & Mann-Whitney Test (p-value) \\
\hline & \multirow[t]{2}{*}{ Physical } & DMFT $>0$ & 85.71 & 85.69 & 10.08 & 0.7900 \\
\hline & & $\mathrm{DMFT}=0$ & 85.72 & 86.01 & 12.87 & \\
\hline & \multirow[t]{2}{*}{ Psychological } & DMFT $>0$ & 79.17 & 78.47 & 12.91 & 0.1000 \\
\hline & & $\mathrm{DMFT}=0$ & 72.91 & 73.96 & 11.26 & \\
\hline & \multirow[t]{2}{*}{ Socializing } & DMFT $>0$ & 58.33 & 56.94 & 15.89 & $0.0210^{*}$ \\
\hline & & $\mathrm{DMFT}=0$ & 50.00 & 45.83 & 12.56 & \\
\hline & \multirow[t]{2}{*}{ Environment } & DMFT $>0$ & 78.13 & 75.41 & 14.28 & 0.3190 \\
\hline & & $\mathrm{DMFT}=0$ & 73.44 & 72.14 & 12.39 & \\
\hline & \multirow[t]{2}{*}{ WHOQOL-Bref score } & DMFT $>0$ & 87.50 & 83.85 & 15.07 & 0.1310 \\
\hline & & $\mathrm{DMFT}=0$ & 81.25 & 77.08 & 16.71 & \\
\hline & \multirow[t]{2}{*}{ OIDP score } & DMFT $>0$ & 0 & 6.39 & 9.19 & 0.2930 \\
\hline & & $\mathrm{DMFT}=0$ & 5,00 & 7,92 & 8,91 & \\
\hline
\end{tabular}

* statistically significant association.

Table 4. Associations of quality of life with dental service accessibility.

\begin{tabular}{|c|c|c|c|c|c|c|}
\hline The last dental consultation & Physical & Psychological & Socializing & Environment & $\begin{array}{l}\text { WHOQOL } \\
\text { score }\end{array}$ & $\begin{array}{l}\text { OIDP } \\
\text { score }\end{array}$ \\
\hline \multicolumn{7}{|l|}{ Period } \\
\hline $\begin{array}{l}\text { The last } 12 \text { months } \\
\text { More than one year }\end{array}$ & 0.5308 & 0.6550 & 0.9410 & 0.2500 & $0.0475^{*}$ & 0.3638 \\
\hline \multicolumn{7}{|l|}{ Health service type } \\
\hline $\begin{array}{l}\text { Public } \\
\text { Private }\end{array}$ & 0.7471 & 0.2070 & $0.0337^{*}$ & 0.3119 & 0.0519 & 0.5725 \\
\hline \multicolumn{7}{|l|}{ Cause } \\
\hline $\begin{array}{l}\text { Pain } \\
\text { Routine and prevention }\end{array}$ & 0.5407 & 0.8302 & 0.5775 & 0.8856 & 0.1546 & 0.1622 \\
\hline \multicolumn{7}{|l|}{ Consultation } \\
\hline $\begin{array}{l}\text { Good } \\
\text { Bad }\end{array}$ & 0.9291 & 0.4962 & $0.0306^{*}$ & 0.2928 & 0.2624 & 0.2362 \\
\hline \multicolumn{7}{|l|}{ Preventive education } \\
\hline $\begin{array}{l}\text { Yes } \\
\text { No }\end{array}$ & 0.4189 & 0.0972 & 0.1502 & $0.0045^{*}$ & 0.3183 & 0.5117 \\
\hline \multicolumn{7}{|l|}{ Self-perception of treatment needs } \\
\hline $\begin{array}{l}\text { Yes } \\
\text { No }\end{array}$ & 0.4392 & 0.1090 & 0.2776 & 0.1802 & 0.3661 & 0.3060 \\
\hline
\end{tabular}

* statistically significant association.

to need dental treatment ${ }^{1}$. Unfortunately, adolescents seek dental treatment because of dental problems, instead of seeking regular and preventive consultation ${ }^{17,18}$.

The expected outcome of this attitude, which is part of rural culture, in addition to the difficulty of access to dental services and shortage of capable professionals ${ }^{9}$, is poor oral health, with negative effects on learning and academic development ${ }^{19}$. The prevalence of conditions causing toothache among adolescents demonstrates the need for public health policies that consider the difficulties faced by these socially excluded populations and aim to reduce caries prevalence and promote oral health maintenance through preventive, educational, and interventional measures focused on quality of life ${ }^{20}$.

Fear may be one reason for rare treatment seeking and may also explain the high caries index because it can prevent individuals from ob- 
taining care except when they experience severe toothache. This situation likely reflects the worsening of caries and has a bad prognosis, possibly ending in tooth loss ${ }^{19}$.

Adolescents' conceptualization and valuation of oral health must also be considered such as the social representation of oral problems among them ${ }^{16}$; those who do not value oral health tend to have the worst hygiene habits, lowest frequency of consultations, and, thus, worst oral health ${ }^{15,21}$. Tooth loss and large and numerous carious lesions are common in patients who experience fear or high levels of anxiety during dental consultation ${ }^{19}$.

Health education should begin in childhood because conceptualization of the meaning of health and the importance of maintaining systemic health and preventive habits persists into adulthood. Adolescents who lack health information, particularly those in rural communities, are more likely to experience severe tooth loss in adulthood with negative effects on quality of life ${ }^{4,21}$.

Poor oral health affects individuals' social life, chewing, and tooth cleaning ${ }^{21}$. However, despite these effects on many aspects of quality of life, individuals' satisfaction with their dental appearance worsens from adolescence to adulthood, suggesting worsening oral health conditions and lack of care ${ }^{22}$. In the transition to adulthood, individuals acquire harmful habits such as tobacco use, alcohol consumption, and impoverishment of oral hygiene, making the oral condition more vulnerable to dental problems ${ }^{22}$. OIDP indices were low in the present study, demonstrating that oral health impacted adolescents' quality of life The relation found between presence of caries and social relationships in the present study indicated the mild impact of oral health on quality of life.

The negative effects of oral health on quality of life are due mainly to gingivitis and dental calculus, which prevent adolescents from smiling because of embarrassment about their appearance and halitosis. In addition, severe untreated caries cause pain, suffering, and discomfort, preventing individuals from relaxing, making them more sentimental, and making concentration on their studies difficult; in other words, these oral health problems clearly damage adolescents' social life ${ }^{1}$. The oral problems measured by the OIDP index cause difficulties with smiling, sleeping, eating, and tooth cleaning due to pain and discomfort ${ }^{14}$.

Another relevant problem caused by the worsening of caries, lack of preventive care, and rarity of dental consultation among adolescents is absenteeism from school, which increases the impact of oral health on quality of life ${ }^{1}$. This situation is worse in adolescents who lives in rural communities, given the difficulty of accessing schools and the severe pain resulting from poor oral health; in addition to the effects of poor valuation of oral health, these factors combine to make school absenteeism normal fin this population ${ }^{1}$, like the studied adolescents from settlement. Teenagers with severe caries and toothache due to large numbers of decayed and untreated teeth tend to be absent from school more than those with low caries indices ${ }^{1}$.

The present analysis showed no significant association between quality of life indices and variables measuring the need for dental treatment and periodontal condition, perhaps due to the small amount of discomfort caused by gingival bleeding. Tooth brushing at least twice a day and daily use of dental floss are directly related to good oral hygiene and periodontal condition ${ }^{23}$. Parents' education level is not associated with their children's periodontitis, and this disease is usually not a reason for dental consultation ${ }^{23}$.

The association between timing of the last consultation and quality of life was higher among adolescents who made frequent visits to the dentist suggesting that routine dental consultations can improve the quality of life.

Infrequent dental visits and lengthy intervals before individuals seek treatment are directly related to the pronounced impacts of oral health on quality of life, high caries index, and dissatisfaction with oral health ${ }^{17}$. Parents who have taken their children to the dentist since childhood tend to encourage their children to continue this habit in adolescence, promoting better valuation of oral health and preventive actions ${ }^{24}$.

The studied adolescents who attended public health services presented worst quality of life than those who seek for private services, demonstrating that the type of care offered to population is important to maintenance of their quality of life.

Rural communities tend to use more public health services than the urban, likely due to the shortage of private services in rural and remote areas ${ }^{17}$, similarly the study population who sought dental treatment in public services. Generally, the poor environment domain is related to low social and economic classes ${ }^{25}$, but in the study population all of participants belonged to the same class, which suggested differences in dental consultations between public and private services. 
Professionals find working in rural areas very difficult because of the limited social life, professional isolation, workload, dissatisfaction with health center infrastructure, difficulty of attending educational courses, and lack of information about other job opportunities ${ }^{26}$. Thus, health care providers working in remote communities tend to demonstrate professional unpreparedness, lack of affinity with this kind of work, and lack of professional commitment to promote health, all of which contribute further to social exclusion.

The difficulty of accessing dental services, whether public or private, is not the only factor contributing to poor dental and periodontal conditions in adolescents. Education level, receipt of information about oral health, frequency and quality of tooth brushing, regularity of dental visits, and sugar ingestion are also worst in rural communities, especially those far from urban capitals ${ }^{17}$. For these reasons, dental caries is more prevalent among adolescents from rural and remote areas than among urban adolescent ${ }^{27}$, with decayed and untreated teeth suggesting lack of care and harmful habits that directly affect quality of life, principally in the psychological, social, and physical domains ${ }^{17}$.

The negative influence found of environment in oral health education for the studied adolescents from settlement suggested some failing in preventive works in public health services.

Satisfaction with one's environment, educational level, and positive perception of parents' health seem to be associated with better oral health conditions and less psychological impact of poor oral health among adolescents. Conversely, the damage caused by worsening dental problems negatively affects quality of life and limits dental function, resulting in poor self-perceived oral health and worse self-esteem ${ }^{28,29}$. Self-esteem is related to self-efficiency in oral care, which is better in boys than in girls; in addition, this self-efficiency seems to be worse in adolescents who live with a single parent than in those who live with both parents ${ }^{30}$.

The impact of oral health, especially regarding decayed and missing teeth, on the psychological domain can be sufficiently large to contribute to depression ${ }^{31}$. This situation has gained attention from researchers because oral health is directly linked to health related quality of life. A high caries index reflects the urgent need for immediate care to avoid worsening of the condition and irreparable loss $s^{30}$, especially in socially excluded populations, which typically have the worst oral health conditions and show the greatest impacts on quality of life ${ }^{2}$.

Although, there are few works investigating oral health and quality of life of populations from rural settlement, mainly with adolescents. New studies focused on them would clarify some peculiarities, like their life style and habits, to help the health professionals comprehending them and also to support new public health policies which would make easier the dental service accessibility and consequently, contribute to better quality of life of these adolescents.

It was concluded that the caries index was high among adolescents from rural settlement in Pontal do Paranapanema (SP). The most evident periodontal change was gingival bleeding, which is a reversible condition. Dental treatment needs included restoration and instruction in oral hygiene and prophylaxis. Adolescents from settlement continue to face inequity in access to dental services; in the majority of the study population, the last dental consultation occurred more than 12 months previously, in the public sector, due to toothache. Although participants reported good quality of life and a low impact of oral health, the social relationships of these socially excluded adolescents were influenced by the presence of dental caries and type and quality of the last consultation. 


\section{Collaborations}

MM Leão contributed to design of study, acquisition of data, analysis and interpretation of data, and in drafting the manuscript. CAS Garbin contributed to design and acquisition of data, mainly concerning ethical aspects; was involved in drafting the manuscript, revising it critically for important intellectual content and contributed to analysis and interpretation of data. SAS Moimaz contributed to design and acquisition of data, mainly concerning epidemiological aspects; contributed to analysis and interpretation of data and gave the final approval of the version to be published. TAS Rovida contributed to conception and design of research, in drafting the manuscript, analysis and interpretation of data, and gave final approval of version to be published. All authors read and approved the final manuscript.

\section{References}

1. Krisdapong S, Prasertsom P, Rattanarangsima K, Sheiham A. Relationships between oral diseases and impacts on Thai schoolchildren's quality of life: evidence from a Thai national oral health survey of 12-and 15-year-olds. Community Dent Oral Epidemiol 2012; 40(6):550-559.

2. Papaioannou W, Oulis CJ, Latsou D, Yfantopoulos J. Oral health related quality of life of Greek adolescents: a cross-sectional study. Eur Arch Paediatr Dent 2011; 12(3):146-150.

3. Mashoto KO, Astrøm AN, David J, Masalu JR. Dental pain, oral impacts and perceived need for dental treatment in Tanzanian school students: a cross-sectional study. Health Qual Life Outcomes 2009; 7:73.

4. Saliba NA, Moimaz SAS, Saliba O, Tiano AVP. Dental loss in a rural population and the goals established for the World Health Organization. Cien Saude Colet 2010; 15(Supl. 1):1857-1864.

5. Tolvanen M, Lahti S, Miettunen J, Hausen H. Relationship between oral health-related knowledge, attitudes and behaviors among 15-16-year-old adolescents: a structural equation modeling approach. Acta Odontol Scand 2012; 70(2):169-176.

6. Barbato PR, Peres MA. Tooth loss and associated factors in adolescent: a Brazilian population-based oral health survey. Rev Saude Publica 2009; 43(1):13-25.

7. Brazil. Ministry of Health (MH). SB Brazil 2003 Project: oral health status of the population 2002-2003: main results. Brasília: MH; 2004.

8. Brazil. Ministry of Health (MH). SB Brazil 2010 Project: national research on oral health: main results. Brasília: $\mathrm{MH} ; 2011$.

9. Frieden TR, Henninh KJ. Public health requirements for rapid progress in global health. Glob Public Health 2009; 4(4):323-337.

10. Scopinho RA. Life and health conditions of a worker in a rural settling. Cien Saude Colet 2010; 15(Supl. 1):1575-1584.

11. Fleck MPA, Louzada S, Xavier M, Chachamovich E, Vieira G, Santos L, Pizon V. Application of the Portuguese version of the abbreviated instrument of quality life WHOQOL-bref. Rev Saude Publica 2000; 34(2):178-183.

12. Castro RAL, Corte MIS, Leão AT, Portela MC, Souza IPR, Tsakos G, Mercedes W, Sheiham A. Child-OIDP index in Brazil: Cross-cultural adaptation and validation. Health Qual Life Outcomes 2008; 6:68.

13. World Health Organization (WHO). Global School-based Student Health Survey (GSHS) 2009. [cited 2013 Mar 13]. Available from: http://www.who.int/chp/gshs/ GSHS_Questionnaire_Core_Expanded_2009_English. pdf

14. Machado GCM, Daher A, Costa LR. Factors associated with no dental treatment in preschoolders with toothache: a cross-sectional study in outpatient public emergency services. Int J Environ Res Public Health 2014; 11(8):8058-8068.

15. Ravaghi V, Quiñonez C, Allison PJ. Oral pain and its covariates: findings of a Canadian population-based study. J Can Dent Assoc 2013; 79:d3.

16. Abreu MHNG, Pordeus IA, Modena CM. A social representation study of oral health among mothers in rural areas, Itaúna (MG), 2002. Cien Saude Colet 2005; 10(1):245-259. 
17. Crocombe LA, Broadbent JM, Thomson WM, Brennan DS, Poulton R. Impact of dental visiting trajectory patterns on clinical oral health and oral health-related quality of life. J Public Health Dent 2011; 72(1):36-44.

18. Garbin CAS, Garbin AJI, Arcieri RM, Saliba NA, Gonçalves PE. La salud bucal en la percepción del adolescente. Rev Salud Publica 2009; 11(2):268-277.

19. Seirawan H, Faust S, Mulligan R. The impact of oral health on the academic of disadvantaged children. Am J Public Health 2012; 102(9):1729-1734.

20. Kumar YS, Acharya S, Pentapati KC. Prevalence of dental pain and its relationship to caries experience in school children of Udupi District. Eur Arch Paediatr Dent 2014; 15(6):371-375.

21. Coolidge T, Skaret E, Heima M, Johnson EK, Hillstead MB, Farjo N, Asmyhr O, Weinstein P. Thinking about going to the dentist: a Contemplation Ladder to assess dentally-avoidant individuals' readiness to go to a dentist. BMC Oral Health 2011; 11:4.

22. Åstrøm AN, Wold B. Socio-behavioural predictors of Young adults' self-reported oral health: 15 years of follow-up in the The Norwegian Longitudinal Health Behaviour study. Community Dent Oral Epidemiol 2012; 40(3):210-220.

23. Vadiakas G, Oulis CJ, Tsinidou K, Mamai-Homata E, Polychronopoulou A. Socio-behavioural factors influencing oral health of 12 and 15 year old Greek adolescents: a national pathfinder survey. Eur Arch Paediatr Dent 2011; 12(3):139-145.

24. Peres KG, Peres MA, Araujo CLP, Menezes AMB, Hallal PC. Social and dental status along the life course and oral health impacts in adolescents: a population-based birth cohort. Health Qual Life Outcomes 2009; 7:95.

25. Gordia AP, Quadros TMB, Campos W. Sociodemographic variables as determinant of the environment domain of quality of life of adolescents. Cien Saude Colet 2009; 14(6):2261-2268.
26. Godwin DM, Hoang H, Crocombe LA, Bell E. Dental practitioner rural work movements: a systematic review. Rural Remote Health 2014; 14(3):2825.

27. Frias AC, Antunes JLF, Junqueira SR, Narvai PC. Determinantes individuais e contextuais da prevalência de cárie dentária não tratada no Brasil. Rev Panam Salud Publica 2007; 22(4):279-285.

28. Baker SR, Mat A, Robinson PG. What psychosocial factors influence adolescents' oral health? J Dent Res 2010 89(11):1230-1235.

29. Costa MCO, Bigras M. Personal and collective mechanisms for protecting and enhancing the quality of life during childhood and adolescence. Cien Saude Colet 2007; 12(45):1101-1109.

30. Kvarme LG, Haraldstad K, Helseth S, Sorum R, Natvig $\mathrm{K}$. Associations between general serf-efficacy and health-related quality of life among 12-13-year-old school children: a cross-sectional survey. Health Qual Life Outcomes 2009; 7:85.

31. Seirawan H, Sundaresan S, Mulligan R. Oral health-related quality of life and perceived dental needs in the United States. J Public Health Dent 2011; 71(3):194201

Artigo apresentado em 01/12/2014

Aprovado em 18/03/2015

Versão final apresentada em 20/03/2015 